EDITORIAL

\title{
Criar e manter um periódico científico: discutindo a sustentabilidade das revistas acadêmicas no campo da História
}

\author{
Creating and Maintaining a Scientific Journal: Discussing the \\ Sustainability of Academic Journals in the Field of History
}

Em maio do presente ano, fomos surpreendidos com a notícia da suspensão definitiva das atividades da revista Estudos de Literatura Brasileira Contemporânea, da Universidade de Brasília, em circulação desde 1999, avaliada como A1 no Qualis Capes, além de presente em alguns dos mais importantes indexadores da atualidade. A principal razão alegada é o desaparecimento de editais de apoio às publicações no Brasil, bem como a falta de suporte institucional, em função do desmonte dos recursos para a universidade pública, sobretudo na área de Humanidades. No mês seguinte, um manifesto assinado pela Academia Brasileira de Ciências (ABC), pela Academia Brasileira de Letras (ABL), pela Academia Nacional de Medicina (ANM) e pela Sociedade Brasileira para o Progresso da Ciência (SBPC) torna público um idêntico problema de falta de financiamento para as revistas científicas, demonstrando que as preocupações não estão apenas nas Ciências Humanas (cf. Situação dos Periódicos Científicos..., 2021). Na carta aberta que as editoras e os editores da Estudos de Literatura escrevem para informar a triste notícia fica claro, no entanto, que a questão era financeira, mas não apenas, já que o imenso trabalho exigido na editoração das mesmas "não ‘dá pontos' no currículo, não conta na carga horária, não é remunerado e não recebe praticamente nenhum apoio ou mesmo reconhecimento." (Dalcastagnè et al., 2021).

Longe estamos de querer insinuar que o financiamento à produção das revistas é secundário. Ainda mais no campo das Humanidades, em que a gratuidade no acesso e na publicação ${ }^{1}$ é uma bandeira defendida por muitas e muitos de nós como a melhor forma de atuação e divulgação do conhecimen- 
to por nós produzido, não muitas vezes efetivamente pago com dinheiro público. Sendo assim, a carta editorial traz à tona problemas que afetam e dificultam diretamente a produção dos periódicos na nossa área no Brasil. Além das dificuldades financeiras, há outras que dizem respeito à valorização dos periódicos, aos vários trabalhos imprescindíveis para sua confecção e ao reconhecimento da função de editores e pareceristas. Se isso afeta as revistas mais consolidadas e mais bem avaliadas, o que dizer em relação às mais recentes e menos indexadas, inclusive com iniciativas inovadoras, em que cada edição "subida ao ar" parece ter o sabor de uma verdadeira vitória olímpica? Para o bem e para o mal, digamos.

Comecemos pelos custos tangíveis. Uma questão com a qual editores menos experientes sempre ficam surpresos, da mesma forma que aqueles que nunca trabalharam diretamente no ofício da editoração, diz respeito aos gastos de manutenção de um periódico científico. Ledo engano imaginar que, por não ser impresso, seu custo seria muito mais barato - o que pode valer apenas para as iniciativas em que seus editores e conselheiros realizam grande parte das tarefas essenciais. Segundo dados da SciELO Brasil, o custo médio por artigo publicado em sua base é de $\mathrm{R} \$ 1.600,00$ (Packer, 2019, slide 3), quando cumpridas todas as etapas citadas abaixo. Um custo considerável, ainda mais quando se defende a opção de que seu público não pague nem para publicar, tampouco para acessar. Ou seja, publicar artigos de qualidade é caro, e publicar artigos em língua estrangeira, mais caro ainda!

Mas, o que poderíamos chamar de custos? De modo geral, tendo como ponto de partida os estudos e as análises que tratam do tema (Johnson; Watkinson; Mabe, 2018), bem como os periódicos na nossa área, podemos considerar que os custos de manutenção de um periódicos são dos seguintes tipos:

(a) Custo de edição do artigo: valores envolvidos diretamente no tratamento do artigo em si, como revisão textual, eventualmente em mais de uma língua, padronização, DOI, diagramação, marcação XML, sistema antiplágio;

(b) Custo de infraestrutura: valores envolvidos na manutenção da plataforma de gerenciamento do fluxo editorial e demais custos editoriais que não estão diretamente associados ao artigo e ao pessoal;

(c) Custo de pessoal: equipe que dá suporte ao processo editorial e que, no geral, envolve secretários e assistentes, e toda a espécie de trabalho em que houver relação remuneratória;

(d) Custos intangíveis: todos aqueles associados ao trabalho voluntário, 
que, entre nós, cabem sempre aos editores e às equipes/aos conselhos editoriais - os quais, não poucas vezes, assumem outras tarefas de edição de artigos, em função da diminuição do orçamento (revisão, diagramação, tradução) -, mas também aos avaliadores/pareceristas.

Sendo assim, os custos estão associados a duas grandes categorias: (a), (b) e (c) são pagos em espécie; enquanto que (d) é indireto, já que a contrapartida à realização do trabalho não é efetivamente financeira.

Considerando essas questões, redobra-se a importância de se afrontar o problema da sustentabilidade, e mesmo de se ampliar o escopo que inicialmente ele pode aparentar. Para além da sustentabilidade financeira, há outra, de caráter "operacional", mas bem humana, que depende muito daquelas e daqueles envolvidos com a causa do periódico ${ }^{3}$. Dimensão esta que não se reduz aos editores e às equipes, mas que merece ser pensada em dois outros níveis, ao menos. Primeiramente, na capacidade do periódico de captar um fluxo de artigos de qualidade, condizente com o número de publicação de artigos da área. Movimento que necessita de certa adesão da comunidade ao periódico, não apenas no sentido de lhe enviar contribuições (na forma de textos, propostas de dossiês, etc.), mas de acompanhá-lo e citá-lo, evitando que haja uma permanente preocupação com a busca e/ou a encomenda de textos a cada edição. Neste sentido, a criação de um projeto editorial de curto e médio prazo, que vise ocupar uma lacuna nos veículos de comunicação científicos da área, bem como um projeto de comunicação e divulgação científica fazem-se fundamentais, sobretudo aos periódicos que venham a ser criados.

Em um segundo nível, e de forma ainda mais sensível, está a capacidade de mobilização de pareceristas ad hoc para darem subsídios aos editores no processo de avaliação. Não deve existir editor de revistas na nossa área que passe ileso diante das dificuldades na busca, na substituição e na encomenda de pareceres de qualidade, para que se evitem maiores delongas na publicação de um texto - celeridade que termina sendo um critério importante na credibilidade dos periódicos, sobretudo dos mais novos. Todos sabemos como os pareces são ineludíveis, envolvendo expertises incomensuráveis do ponto de vista financeiro, e o processo de avaliação parte da "alma" das revistas para promover a publicação de trabalhos originais e de qualidade. Assim sendo, caberia perguntar: porque essa avaliação é tão pouco quantificada quando falamos de critérios de produção acadêmica e mesmo da carreira do pesquisador?

Com isso, tocamos num ponto nevrálgico: nos últimos anos, o campo valorizou muito a publicação de artigos, sobretudo em revistas de altos estratos, mas não deu a mesma importância ao trabalho editorial, incluindo a ati- 
vidade especializada de peer-review ${ }^{4}$. O mesmo se pode dizer das universidades em geral, e dos critérios de avaliação da produção docente para ascensão na carreira e para atribuição de outras atividades nos departamentos - pois, embora ser editor e/ou membro de algum conselho editorial possa ter algum prestígio em casos específicos, o mesmo não se revela em termos de mensuração do tempo dispendido na tarefa. Da mesma maneira, a produção editorial realizada por discentes dificilmente se reverte em créditos e/ou formas de notabilizar iniciativas criativas por parte dos estudantes.

Para tudo isso, o financiamento segue sendo fundamental. Vale dizer que, enquanto pensávamos essas páginas, foi publicado pelo CNPq o edital para fomento de periódicos ${ }^{5}$. Sua reedição, depois de mais de dois anos sem a implementação desse auxílio, reforça a necessidade de reflexionarmos sobre nosso padrão de sustentabilidade. Por um lado, porque o edital continua valorizando apenas as revistas de altíssimos estratos, sem criar modos de favorecer iniciativas inovadoras - mantém-se, igualmente, um certo descaso às especificidades das áreas das Humanidades, que dependem prioritariamente dos seus recursos. Por outro lado, porque ele sozinho é incapaz de resolver outras variáveis fundamentais para a criação de uma cultura sustentável de manutenção dos periódicos no nosso campo, qual seja, a do reconhecimento das revistas e do trabalho editorial, em todos os seus níveis, como vitais à produção científica. Cabe à nossa comunidade encarar a questão de frente, sem abrir mão de lutar pela política de acesso aberto e gratuito aos nossos periódicos.

Andréa Slemian*
* Universidade Federal de São Paulo (UNIFESP), Escola de Filosofia, Letras e Ciências Humanas, Guarulhos, SP, Brasil. slemian@unifesp.br <https://orcid.org/0000-0002-2745-7073>

Marcos Eduardo de Sousa ${ }^{* *, * * *}$

** Centro Federal de Educação Tecnológica de Minas Gerais (CEFET-MG), Belo Horizonte, Minas Gerais, Brasil. *** Universidade Federal de Ouro Preto (UFOP), Instituto de Ciências Humanas e Sociais, Sistema de Biblioteca e Informação, Mariana, Minas Gerais, Brasil. medsmg@gmail.com <https://orcid.org/0000-0002-8327-030X> 


\section{REFERÊNCIAS}

CHAMADAS PÚBLICAS. 2021. Disponível em: http://memoria.cnpq.br/chamadas-publicas. Acesso em: 7 set. 2021.

DALCASTAGNÈ, Regina et al. Nota dos editores da Revista Estudos de Literatura Brasileira Contemporânea. Anpoll: Associação Nacional de Pós-Graduação e Pesquisa em Letras e Linguística. 26 mai. 2021. Disponível em: https://anpoll.org. $\mathrm{br} / 2021 / 06 / 07 /$ nota-dos-editores-da-revista-estudos-de-literatura-brasileira-contemporanea-2/. Acesso em: 6 set. 2021.

JOHNSON, Rob; WATKINSON, Anthony; MABE, Michael. The STM Report: An Overview of Scientific and Scholarly Publishing. STM: International Association of Scientific, Technical and Medical Publishers. 2018. Disponível em: https://www. stm-assoc.org/2018_10_04_STM_Report_2018.pdf. Acesso em: 27 nov. 2019.

NASSI-CALÒ, Lilian. Avaliação por pares aberta: a publicação dos pareceres influencia o comportamento dos pareceristas? SciELO em Perspectiva. 27 mar. 2019a. Disponível em: https://blog.scielo.org/blog/2019/03/27/avaliacao-por-pares-aberta-a-publicacao-dos-pareceres-influencia-o-comportamento-dos-pareceristas/. Acesso em: 7 set. 2021.

NASSI-CALÒ, Lilian. Potenciais vantagens e desvantagens na publicação de pareceres. SciELO em Perspectiva. 30 abr. 2019b. Disponível em: https://blog.scielo.org/ blog/2019/04/30/potenciais-vantagens-e-desvantagens-na-publicacao-de-pareceres/. Acesso em: 7 set. 2021.

OHARA, João Rodolfo Munhoz. Podemos discutir a avaliação aberta em uma disciplina conservadora? História da Historiografia: International Journal of Theory and History of Historiography, Ouro Preto, v. 14, n. 35, pp. 11-17, 2021.

PACKER, Abel L. SciELO - Estado de avanço e perspectivas futuras. VIII Reunião Anual do SciELO. 2019. Disponível em: https://www.slideshare.net/scielo/abel-packer-scielo-estado-de-avano-e-perspectivas-futuras. Acesso em: 14 mai. 2020.

SCIELO BRASIL. Critérios, política e procedimentos para a admissão e a permanência de periódicos na Coleção SciELO Brasil. SciELO Brasil. 13 mai. 2020. Disponível em: https://wp.scielo.org/wp-content/uploads/20200500-Criterios-SciELO-Brasil. pdf. Acesso em: 28 jun. 2020.

SITUAÇÃO DOS PERIÓDICOS CIENTÍFICOS brasileiros. Academia Brasileira de Ciências. 11 jun. 2021. Disponível em: http://www.abc.org.br/2021/06/11/manifestacao-situacao-dos-periodicos-cientificos-brasileiros/. Acesso em: 28 jun. 2020.

\section{NOTAS}

${ }^{1}$ Ou seja, a não realização de cobranças às autoras e aos autores em nenhuma etapa do processo de publicação (taxas de submissão, publicação - APC, revisão e outras). 
${ }^{2} \mathrm{O}$ custo de revisão de língua estrangeira é entre duas e cinco vezes o custo de revisão em português, a depender da língua estrangeira.

${ }^{3}$ Ver o documento "Critérios, política e procedimentos para a admissão e a permanência de periódicos na Coleção SciELO Brasil” (Scielo Brasil, 2020).

${ }^{4}$ No caso brasileiro, o SciELO passou a incentivar, dentro da dimensão de abertura do processo de avaliação promovida pela rede, “a opção de publicar os pareceres de aprovação de artigos com ou sem a identificação dos pareceristas. Os pareceres constituem um novo tipo de literatura na metodologia SciELO e recebem tratamento similar aos artigos de pesquisa." (Scielo Brasil, 2020, p. 7). No entanto, ainda cabe, sobretudo às Ciências Humanas, uma discussão entre a comunidade das implicações disso em sua prática. Uma reflexão inicial sobre a abertura de avaliação, na área de História, pode ser vista em João Ohara (2021), enquanto uma discussão acerca dos impactos entre os pareceristas e dos prós e contras da publicação de pareceres pode ser vista em Lilian Nassi-Calò (2019a, 2019b).

${ }^{5}$ Conferir a chamada n. 15/2021 do Programa Editorial (Chamadas Públicas, 2021). 